\title{
Development and Validation of a Spanish Version of the Grit-S Scale
}

\author{
Jose L. Arco-Tirado ${ }^{1 *}$, Francisco D. Fernández-Martín ${ }^{1}$ and Rick H. Hoyle ${ }^{2}$ \\ ${ }^{1}$ Department of Development and Educational Psychology, University of Granada, Granada, Spain, ${ }^{2}$ Department of \\ Psychology and Neuroscience, Duke University, Durham, NC, United States
}

This paper describes the development and initial validation of a Spanish version of the Short Grit (Grit-S) Scale. The Grit-S Scale was adapted and translated into Spanish using the Translation, Review, Adjudication, Pre-testing, and Documentation model and responses to a preliminary set of items from a large sample of university students $(N=1,129)$. The resultant measure was validated using data from a large stratified random sample of young adults $(N=1,826)$. Initial validation involved evaluating the internal consistency of the adapted scale and its subscales and comparing the factor structure of the adapted version to that of the original scale. The results were comparable to results from similar analyses of the English version of the scale. Although the internal consistency of the subscales was low, the internal consistency of the full scale was

OPEN ACCESS

Edited by:

Jin Eun Yoo,

Korea National University of

Education, South Korea

Reviewed by:

Tova Stenlund

Umeå University, Sweden

Riccardo Sartori,

University of Verona, Italy

Bert Jonsson,

Umeå University, Sweden

*Correspondence:

Jose L. Arco-Tirado jlarco@ugr.es

Specialty section:

This article was submitted to Quantitative Psychology and Measurement, a section of the journal Frontiers in Psychology

Received: 03 October 2017 Accepted: 22 January 2018 Published: 07 February 2018

Citation:

Arco-Tirado JL, Fernández-Martín FD and Hoyle RH (2018) Development and Validation of a Spanish Version of the Grit-S Scale. Front. Psychol. 9:96. doi: 10.3389/fpsyg.2018.00096 well-within the acceptable range. A two-factor model offered an acceptable account of the data; however, when a single correlated error involving two highly similar items was included, a single factor model fit the data very well. The results support the use of overall scores from the Spanish Grit-S Scale in future research.

Keywords: grit, non-cognitive skills, goal pursuit, scale validation, passion and perseverance

\section{INTRODUCTION}

People vary in their typical response to adversity or failure when pursuing important long-term goals. Whereas some people are steadfast in their pursuit of such goals, sometimes over years, or decades, other people abandon pursuit in the face of significant challenges to the attainment of such goals. This variability is captured by the grit construct, defined as trait-level passion for and perseverance in pursuing long-term goals (Duckworth et al., 2007).

Within the Big Five taxonomy of personality traits, grit shares content with conscientiousness domain (Rimfeld et al., 2016) as reflected in its conceptual relatedness to several of the conscientiousness facets-orderliness, dependability, self-control, and industriousness (Duckworth and Eskreis-Winkler, 2015). Indeed, grit is view by some personality theorists as falling with the broad family of conscientiousness constructs (Roberts et al., 2014). Yet, despite its conceptual similarity to facets of conscientiousness, none of the conscientiousness facets fully captures the combination of passion and perseverance that characterizes grit. In particular, the sustained interest in important long-term goals, a core feature of grit, is not evident in conscientiousness or its facets (Sartori et al., 2017). Thus, although the conceptual overlap between the broad conscientiousness domain and the relative narrow grit trait is substantial, conceptually speaking, grit includes a specific and unique focus on the pursuit of long-term, higher-order goals.

The predictive validity of grit is evident in its prospective association with consequential outcomes that involve persistence in the pursuit of important goals. For example, controlling for cognitive ability, grit predicts educational attainment and fewer career changes in adults and grade 
point average, hours spent watching television (inversely), and retention in adolescents (Duckworth and Quinn, 2009). People higher in grit are more likely to persist on boring tasks and less likely to drop out of college (Yeager et al., 2014). Among new teachers, grit is associated with higher efficacy and greater retention (Duckworth et al., 2009). People higher in grit show greater work engagement (Eskreis-Winkler et al., 2014b), a reduced likelihood of changing professions or jobs (Duckworth et al., 2007; Eskreis-Winkler et al., 2014a), more stable marriages (Eskreis-Winkler et al., 2014a), less counterproductive behaviors (Ceschi et al., 2016), and higher scores on characteristics positively associated with life expectancy (Kim and Lee, 2015). Although the number of studies showing incremental prediction by grit is substantial, the contribution of grit is modest and may attributable primarily to the perseverance feature of the construct (Credé et al., 2017). Of particular concern is the contribution of grit beyond conscientiousness, though, as noted, conscientiousness is a very broad personality construct that encompasses some features of grit as well as other lower-order variables. Grit is relevant primarily for the pursuit of challenging, higher-order goals and, as would be expected, outperforms conscientiousness in the prediction of behaviors that contribute to progress toward achieving such goals (e.g., Tedesqui and Young, 2018).

Individual differences in grit are typically captured using self-report questionnaires. The original Grit Scale comprised 12 items, with half reflecting consistency of interest (i.e., passion) and half reflecting perseverance of effort (i.e., persistence; Duckworth et al., 2007). The focus of the current work is an abbreviated, eight-item version of the scale [Short Grit (Grit-S)], which has better psychometric properties than the longer version, including superior internal consistency, test-retest stability, and convergent and discriminant validity (Duckworth and Quinn, 2009). Factor analyses of both forms of the measure have produced support for the intended two-factor structure, with a moderate correlation between the two dimensions (Duckworth and Eskreis-Winkler, 2015). Although the passion and persistence items often are scored separately, the authors intended for the scale to be used to measure a single compound trait (e.g., Duckworth and Quinn, 2009).

Given the relevance of grit for consequential outcomes in the educational, personal, and professional domains, it is not surprising that the original and short grit scales are widely used across research topics and disciplines. Early work with the construct almost exclusively involved English-speaking respondents; however, recent years have witnessed multiple adaptations of one or both of the measures, including versions in German (Fleckenstein et al., 2014), Korean (Kim and Lee, 2015), Japanese (Nishikawa et al., 2015), Turkish (Akin et al., 2011), and Russian (Tyumeneva et al., 2014). Conspicuously absent is an adaptation of the instrument for use in research involving Spanish-speaking populations.

The objective of the current study was to adapt the Grit$S$ scale for Spanish-speaking respondents and document its psychometric properties. We expected that a Spanish language Grit-S Scale would evidence internal consistency values similar to those reported for the original Grit-S Scale (Duckworth and
Quinn, 2009). Moreover, we expected factor analyses of the adapted items to show that responses could be attributed to two correlated factors, with factor loadings resembling those reported by Duckworth and Quinn (2009) for the English-language Grit-S Scale (cf. Muenks et al., 2017).

\section{METHODS}

The Grit-S Scale items were adapted to be used in a largescale investigation of the cultural pathways to economic selfsufficiency and entrepreneurship and the role that family values play in youth unemployment in 10 European countries. The adapted items were included in the survey administered to young adults in Spain.

\section{Participants}

As part of the adaptation procedure, detailed below, a sample of 1,129 university students responded to an initial translation of the scale (Fernández-Martín et al., 2017). The respondents' average age was 21 years old $(S D=1.7)$ and ranged from 18 to $52 ; 75 \%$ were women. Because some of the items evaluated at this stage were significantly altered to produce the final version of the scale, responses from this sample were not used in the psychometric analyses.

For the primary analyses, a proportional stratified random sampling technique was used with regions (i.e., Nomenclature of Units for Territorial Statistics-2), employment status, age, and sex serving as strata. The resultant sample of 1,826 adults ranged from 18 to 35 years old, with an average age of 27.56 years (SD $=5.00)$, and a distribution by sex comprising 893 men $(48.90 \%)$ and 933 women $(51.10 \%)$. Almost $70 \%$ of the respondents had relatively high levels of education and fewer than a half were employed or self-employed.

\section{Adaptation and Administration}

The procedure to adapt the Grit-S scale followed the recommendations established by specialized literature (Carretero-Dios and Pérez, 2007; Sartori and Pasini, 2007; Muñiz et al., 2013). We followed the translation recommendations in the Cross-Cultural Survey Guidelines, adhering closely to the TRAPD (Translation, Review, Adjudication, Pretesting, and Documentation) team translation model (Survey Research Center, 2016). Our implementation of the model began with a parallel translation from English into Spanish by two bilingual translators with ample experience translating evaluation instruments. Next, a revision committee, composed of the translators and one of the researchers, who is bilingual and a specialist in the development of surveys, analyzed the linguistic, and cultural equivalence of the translations independently produced by the two translators with the original Grit-S Scale. The translated and original items were designated as either: (a) identical, if the meaning of the item and the observed changes were the same, (b) similar if there were changes in the meaning of any of the words but not on the item, or (c) different when there was changes in the meaning of the original item because of the cultural adaptation. Then, the discrepancies derived from the analysis of the linguistic equivalence between members 
of the revision committee were resolved with a second round revision of the items by comparing the original version of the Grit-S Scale with the translation and the revision of the items by the translators and the reviewer together. Finally, a pilot test was implemented with the Spanish version of the Grit-S scale with the sample of university students, whose responses allowed us to examine and to modify some issues related to the implementation of the adaptation process. In particular, due to several queries posed by participants about the concept "diligent" ["diligente"] in item 8 , a note to clarify the meaning was added [i.e., Having or showing care and conscientiousness in one's work or duties (es decir, cuidadoso, activo y que ejecuta con celo y exactitud lo que está a su cargo)]. Furthermore, item number 2, "Los contratiempos no me desaniman" [Setbacks don't discourage me.], was rephrased because the double negative present in the pilot-tested item (and in the original item) in combination with the Strongly disagree response option indicative of high grit, caused confusion for some respondents as evidenced by a loading of only 0.19 on perseverance factor.

The resultant Spanish version of the Grit-S Scale comprises eight items, to which responses are indicated on four-point scales labeled 1 (Strongly disagree), 2 (Somewhat disagree), 3 (Somewhat agree), and 4 (Strongly agree). As with the original version of the scale (Duckworth and Quinn, 2009), the items arrayed in two sets corresponding to the core features of the grit construct, consistency of interest and perseverance of effort. The items are displayed in Table $\mathbf{1 .}$

Once the adaptation was completed, a polling firm, in collaboration with the research team, used the ComputerAssisted Web Interviewing (CAWI) technique to recruit a stratified random sample of members of a panel. Prospective respondents were sent an online invitation and given 14 days to respond. The website through which CAWI was implemented was compatible with different browsers, operating systems, and screen resolutions, and featured a simple and attractive design with security and support mechanisms (Couper and Bosnjak, 2010; Haer and Meidert, 2013). The invitation to panel members provided information on the objectives of the research, the voluntary nature of their participation, and the confidentiality of their responses. Panel members who elected to participate were provided a respondent-specific link to access the Spanish version of the Grit-S Scale. Responses were collected from February to June of 2016.

\section{Data Analysis}

We evaluated the new Spanish version of the Grit-S Scale in two stages. We first computed coefficient alpha for the full scale and the two subscales. Values were interpreted against normative standards and in comparison to values generated in research using the original scale. We then examined the latent structure of the items using confirmatory factor analysis. The a priori model specified two correlated factors corresponding to the item sets identified in Table 1.

We estimated and tested the model using the maximum likelihood estimator as implemented in EQS version 6.3. Although the univariate distributions were approximately
TABLE 1 | Items of the Spanish and Original English Version of the Grit-S Scale arrayed by subscale.

\begin{tabular}{|c|c|}
\hline Consistencia del interés & Consistency of Interest \\
\hline $\begin{array}{l}\text { 1. Las ideas y proyectos nuevos a } \\
\text { veces me distraen de ideas y } \\
\text { proyectos anteriores. }\end{array}$ & $\begin{array}{l}\text { 1. New ideas and projects sometimes } \\
\text { distract me from previous ones. }\end{array}$ \\
\hline $\begin{array}{l}\text { 3. He estado obsesionado/a con } \\
\text { alguna idea o proyecto durante un } \\
\text { tiempo breve, pero después he } \\
\text { perdido el interés. }\end{array}$ & $\begin{array}{l}\text { 3. I have been obsessed with a } \\
\text { certain idea or project for a short time } \\
\text { but later lost interest. }\end{array}$ \\
\hline $\begin{array}{l}\text { 5. A menudo me pongo una meta } \\
\text { pero después cambio a otra diferente. }\end{array}$ & $\begin{array}{l}\text { 5. I often set a goal but later choose } \\
\text { to pursue a different one. }\end{array}$ \\
\hline $\begin{array}{l}\text { 6. Tengo dificultades para mantener } \\
\text { mi atención en proyectos que } \\
\text { requieren más de unos meses en } \\
\text { completarse. }\end{array}$ & $\begin{array}{l}\text { 6. I have difficulty maintaining my } \\
\text { focus on projects that take more than } \\
\text { a few months to complete. }\end{array}$ \\
\hline Perseverancia en el esfuerzo & Perseverance of Effort \\
\hline 2. Los contratiempos me desaniman. & 2. Setbacks don't discourage me. \\
\hline 4. Soy muy trabajador/a. & 4. I am a hard worker. \\
\hline $\begin{array}{l}\text { 7. Termino siempre todo lo que } \\
\text { empiezo. }\end{array}$ & 7. I finish whatever I begin. \\
\hline $\begin{array}{l}\text { 8. Soy diligente (es decir, cuidadoso, } \\
\text { activo y que ejecuta con celo y } \\
\text { exactitud lo que está a su cargo) }\end{array}$ & 8. I am diligent. \\
\hline
\end{tabular}

normal (see the two rightmost columns in Table 2), Mardia's coefficient indicated a modest departure from multivariate normality. Thus, we used robust estimation and scaled statistics as provided in EQS (Satorra and Bentler, 1988). We evaluated the fit of the model by using two widely-used and well-validated fit indices ( $\mathrm{Hu}$ and Bentler, 1999). The comparative fit index (CFI; Bentler, 1990) indexes the proportionate improvement in fit of a specified model over a baseline model in which the observed variables are independent; values between 0.90 and 1.00 are expected for measurement models that fit the data well (Hu and Bentler, 1999). The root mean square error of approximation (RMSEA; Steiger and Lind, 1980) indexes degree of misspecification in a model per degree of freedom, with a value of zero indicating perfect fit to the data and values from zero to 0.10 indicating acceptable fit (Browne and Cudeck, 1993). We put $90 \%$ confidence intervals on the point estimate, expecting the upper limit to fall below 0.10 for a good-fitting model. As is typical, we report but do not interpret the chi-square approximation associated with individual models. These values are used for comparisons of nested models, for which they are appropriate (Steiger et al., 1985). After evaluating a priori models, we examined values of a model modification index in search of residual covariance unaccounted for by the best-fitting a priori model (Chou and Bentler, 1990).

Following evaluation of omnibus fit, we examined parameter estimates, with a particular focus on factor loadings. As with alpha, we interpreted values of loadings with reference to normative standards and in comparison to loadings from similar analyses of the original Grit-S Scale. 
TABLE 2 | Correlations between Translated Grit-S Items and Item-Level Descriptive Statistics.

\begin{tabular}{|c|c|c|c|c|c|c|c|c|c|c|c|}
\hline Subscale/Item & Item 2 & Item 4 & Item 7 & Item 8 & Item 1 & Item 3 & Item 5 & $M$ & $S D$ & Skewness & Kurtosis \\
\hline \multicolumn{12}{|c|}{ PERSEVERANCE OF EFFORT } \\
\hline Item 2 & & & & & & & & 2.289 & 0.826 & 0.34 & -0.35 \\
\hline Item 4 & 0.046 & & & & & & & 3.519 & 0.655 & -0.09 & -0.66 \\
\hline Item 7 & 0.108 & 0.324 & & & & & & 3.092 & 0.794 & -0.45 & -0.53 \\
\hline Item 8 & 0.098 & 0.388 & 0.315 & & & & & 3.423 & 0.638 & -0.74 & -0.14 \\
\hline \multicolumn{12}{|c|}{ CONSISTENCY OF INTEREST } \\
\hline Item 1 & 0.310 & 0.187 & 0.299 & 0.213 & & & & 2.544 & 0.860 & 0.08 & -0.67 \\
\hline Item 3 & 0.233 & 0.105 & 0.196 & 0.130 & 0.382 & & & 2.437 & 0.905 & 0.04 & -0.78 \\
\hline Item 5 & 0.272 & 0.157 & 0.266 & 0.210 & 0.477 & 0.428 & & 2.625 & 0.863 & -0.09 & -0.66 \\
\hline Item 6 & 0.329 & 0.280 & 0.299 & 0.276 & 0.560 & 0.399 & 0.545 & 2.877 & 0.924 & -0.38 & -0.76 \\
\hline
\end{tabular}

All correlation coefficients differ from zero at $p<0.05$.

\section{RESULTS}

Descriptive statistics and correlations between the items are presented in Table 2. The correlations between item 2 and the other items on the perseverance of effort subscale are quite low. Otherwise the correlations range in magnitude from modest to moderate.

Internal consistency estimates for the translated items appear in Table 3. In the top portion of the table are estimates for the current sample. Below these appear representative values of alpha for English-speaking samples who completed the original version of the Grit-S Scale. Looking first to the values for the full set of items, the value of alpha for the current sample is comparable to corresponding values for the comparison samples. Moving to the subscales, the value of alpha for the consistency of interest items is strong and higher than values for three of the four comparison samples. Alpha for the perseverance of effort items is relatively low both in absolute terms and compared to values for the comparison samples, reflecting the low correlations between item 2 and other items in the set (the value of alpha rises to 0.63 if item 2 is omitted). Given the brevity of the subscales, even the low value for the perseverance of effort items is acceptable (i.e., corrected item-total $r$ s range from 0.36 to 0.63 except item $2=$ 0.08; Nunnally and Bernstein, 1994). For the full set of items, all corrected item-total $r$ s, including for item 2 , are $>0.30$ and would reduce the value of alpha if deleted.

Results of the omnibus test of the two-factor model of the translated scale are provided in the top portion of Table 4. As with the evaluation of internal consistency, we provide comparison values for English-speaking samples that completed the original version of the scale. The value of CFI falls within the range of acceptable values. The value of RMSEA meets criterion as well, with a point estimates and upper confidence limit below 0.10 . Values of these indices are consistent with values for prior analysis of the original version of the scale shown in the lower portion of the table. In terms of omnibus fit, the twofactor measurement model provides an acceptable account of the data.

Factor loadings are presented in Table 5. Loadings for the two-factor model are presented in the middle two columns. The
TABLE 3 | Internal Consistency of the Original English and Spanish Versions of the Grit-S Scale.

\begin{tabular}{llcccc}
\hline $\begin{array}{l}\text { Grit-S } \\
\text { version }\end{array}$ & Population & N & Grit-S & $\begin{array}{c}\text { Consistency } \\
\text { of Interest }\end{array}$ & $\begin{array}{c}\text { Perseverance } \\
\text { of Effort }\end{array}$ \\
\hline Spanish & $\begin{array}{l}\text { Adults between 18 } \\
\text { and 35 years old }\end{array}$ & 1826 & 0.75 & 0.77 & 0.48 \\
Original & $\begin{array}{l}\text { West Point 2008 } \\
\text { West Point 2010 }\end{array}$ & 1218 & 0.73 & 0.73 & 0.60 \\
& $\begin{array}{l}\text { 2005 National } \\
\text { Spelling Bee }\end{array}$ & 1708 & 0.76 & 0.74 & 0.65 \\
& $\begin{array}{l}\text { Ivy League } \\
\text { Undergraduates }\end{array}$ & 139 & 0.80 & 0.76 & 0.65 \\
\hline
\end{tabular}

loadings exceed 0.50 for all items except item 2, which, as noted earlier, shares less in common with the remaining perseverance of effort items than would be expected. Nevertheless, the loading for item 2 was noticeably higher than the loading for the initial version of that item on the perseverance factor in the pilot study. The correlation between the two factors was 0.62 , which is somewhat higher than values in the $0.40-0.50$ range observed in analyses of the original scale (e.g., Duckworth et al., 2007; Von Culin et al., 2014) but not inconsistent with the assumption that the factors are constituents of a single construct.

Although the fit of the two-factor model met our omnibus fit criteria, the values of the fit indices, especially RMSEA, suggested that the fit of the model could be improved. As noted earlier, we used a modification index, specifically the Lagrange Multiplier test (Bentler, 1986) of fixed parameters. We focused specifically on covariances between uniquenesses, which convey commonality between items unaccounted for by the two factors. Those tests revealed significant covariance between items 4 (Soy muy trabajador/a., I am a hard worker.) and 8 (Soy diligente, I am diligent.) not accounted for by the perseverance of effort factor and therefore evident in the covariance between their associated uniquenesses. Estimation of a model in which that parameter was freed produced substantially improved fit statistics, scaled $\chi^{2}(18, N=1,826)=235.36, \mathrm{CFI}=0.94, \mathrm{RMSEA}=0.075(\mathrm{CLs}$ 
TABLE 4 | Fit information for the Two-Factor Model for the Spanish and Original Versions of the Grit-S Scale.

\begin{tabular}{|c|c|c|c|c|c|c|c|}
\hline \multicolumn{2}{|c|}{ Grit-S versions/Population } & \multirow{2}{*}{$\begin{array}{c}N \\
1826\end{array}$} & \multirow{2}{*}{$\frac{x^{2}}{325.52}$} & \multirow{2}{*}{$\begin{array}{l}\boldsymbol{d f} \\
19\end{array}$} & \multirow{2}{*}{$\begin{array}{l}\text { CFI } \\
0.92\end{array}$} & \multirow{2}{*}{$\begin{array}{c}\text { RMSEA } \\
0.084\end{array}$} & \multirow{2}{*}{$\begin{array}{c}\mathbf{9 0 \%} \text { Confidence Limits } \\
0.076,0.093\end{array}$} \\
\hline Spanish & Adults between 18 and 35 years old & & & & & & \\
\hline \multirow[t]{5}{*}{ Original } & West Point 2008 & 1218 & 106.36 & 19 & 0.95 & 0.061 & $0.050,0.073$ \\
\hline & West Point 2010 & 1308 & 135.51 & 19 & 0.95 & 0.068 & $0.058,0.080$ \\
\hline & 2005 National Spelling Bee & 175 & 71.57 & 19 & 0.86 & 0.101 & $0.077,0.126$ \\
\hline & Ivy League Undergraduates & 139 & 43.63 & 19 & 0.93 & 0.097 & $0.059,0.135$ \\
\hline & Adults aged 25 and older & 1554 & 188.52 & 19 & 0.96 & 0.076 & $0.066,0.086$ \\
\hline
\end{tabular}

$=0.065,0.083)$, and a highly significant single degree-of-freedom scaled-chi-square difference (Satorra and Bentler, 2001) of 77.90. The loadings on the consistency of interest factor were unaffected by this modification, but the loadings on the perseverance of effort factor differed noticeably: $419,0.348,0.436$, and 0.326 , for items $2,4,7$, and 8 , respectively. The correlation between the item 4-item 8 uniquenesses was 0.40 and, surprisingly, the correlation between the two factors rose to 0.89 .

Given the very high correlation between the two factors in a model with a single correlated uniqueness, we estimated a one-factor model that included the correlated uniqueness. That model, which is consistent with the conceptual model of grit as a single construct comprising passion and perseverance, fit the data exceptionally well, scaled $\chi^{2}(19, N=1,826)=233.21$, $\mathrm{CFI}=0.95$, RMSEA $=0.071(\mathrm{CLs}=0.062,0.080)$. The nested model comparison of the one- and two-factor models indicated minimal loss in fit from adding the simplifying constraint of perfect correlation between the factors, $\Delta$ scaled $\chi^{2}(1)=4.68, p$ $=0.03$. The loadings for the one-factor model with a correlation between uniquenesses for items 4 and $8(r=0.42)$ are presented in the rightmost column of Table 5.

\section{DISCUSSION}

Our goal was to develop a version of the Grit-S Scale for use in research involving Spanish speaking populations. Although the results of internal consistency analyses and confirmatory factor analysis were mixed, they support the use of the scale as originally intended-to assess a single, compound construct. The internal consistency of the full scale is consistent with that of the original scale, and, when a single residual covariance is accounted for, the fit of a single-factor model is excellent. This new version of the measure will help fill a gap in the literature on grit by enabling the inclusion of the Grit-S Scale in studies involving Spanish-speaking populations.

Although the reliability estimates and model fit statistics were in the acceptable range, they were not strong. Importantly, they were consistent with, and occasionally exceeded, comparable values for the original version of the scale as well as translated versions. With respect to reliability, a key consideration is how the measure is to be used. The estimate of internal consistency we observed for the full scale is both comparable to the same estimate in multiple studies using the original version of the scale and within the acceptable range for brief measures.
TABLE 5 | Factor Loadings for the Two- and One-Factor Models.

\begin{tabular}{llll}
\hline Item & Consistency of Interest & Perseverance of Effort & Grit \\
\hline 1 & 0.696 & & 0.696 \\
3 & 0.535 & & 0.541 \\
5 & 0.697 & & 0.694 \\
6 & 0.795 & 0.271 & 0.792 \\
2 & & 0.557 & 0.408 \\
4 & & 0.561 & 0.301 \\
7 & & 0.582 & 0.379 \\
8 & & & 0.282 \\
\hline
\end{tabular}

Importantly, all items contribute to the overall reliability of the measure, with acceptable values of corrected-item correlations and a reduction in coefficient alpha if any item is deleted. The overall value of alpha and value of the inter-item correlations are consistent with a measure characterized by bandwidth as opposed to fidelity (Briggs and Cheek, 1986). That bandwidth, to a large degree, is attributable to the decision to separately assess consistency of interest and perseverance of effort by the original scale developers (Duckworth et al., 2007). In addition, the perseverance of effort items sample a broader domain space than the consistency of interest items, addressing setbacks, finishing what one starts, and hard work. A consequential exception to this bandwidth characterization is the somewhat redundant pair of consistency of interest items that separately refer to diligence and hard work. As our follow-up exploratory analyses revealed, this redundancy is evident in covariance between the responses to these items that is not captured by the perseverance of effort factor. It will be important to examine this feature of the measurement model in independent samples across the languages into which the scale has been translated. If, as we suspect, this residual covariance is evident across populations and translations, the measure would be improved by replacing one of the items with a new item that eliminates the redundancy.

Although the original conceptual model and the results of our analyses support the use of the Grit-S to produce a single score, some researchers may wish to produce separate scores for passion and perseverance. Although our results support producing a score for passion, they do not support doing so for perseverance. In particular, and consistent with recent analyses of the original 
items (Muenks et al., 2017), one of the perseverance items shares little variance with the others as demonstrated by a low corrected item-total correlation in the internal consistency analyses and a low loading in the two-factor model. Importantly, that item performs satisfactorily when internal consistency is evaluated for the full set of items and the responses are fit to a single-factor model. These findings underscore our recommendation that the scale be used to produce a single score, thereby avoiding concerns for this item and better reflecting the full grit construct (e.g., Jachimowicz et al., 2017).

Our promising findings should be interpreted in light of the strengths and limitations of our adaptation and initial evaluation of the translated items. In the absence of prior cultural and linguistic adaptations in Spanish, we were unable to compare our version of the scale with others as recommended (LópezWalle et al., 2011). Our sampling strategy has strengths and potential limitations. Prior studies like ours (e.g., Akin et al., 2011; Nishikawa et al., 2015), including the study in which the original Grit-S scale was evaluated (Duckworth and Quinn, 2009), did not draw random samples, perhaps limiting the representativeness or generalizability of the findings. On the other hand, the representativeness of our sample is unclear because of the digital literacy levels necessary to respond to the survey.

Our evaluation of Spanish-language version of the Grit$S$ Scale suggests that, when used to generate a single score, the scale is comparable to the original scale. As such, we would expect findings using the measure to contribute the broader literature on the role of grit in the pursuit of longterm, higher-order goals. Future research could build on our initial evaluation through an examination of other psychometric properties of the instrument like the test-retest reliability and the predictive validity. That work might also consider the contribution of grit and its constituents to success in long-term goal pursuits in Spanish-speaking populations controlling for

\section{REFERENCES}

Akin, A., Abaci, R., Arici, N., Uysal, R., and Uysal, Ç. K. (2011). "Revised grit scale: the validity and reliability study," Paper presented at the National Education Symposium (Burdur).

Bentler, P. M. (1986). Lagrange Multiplier and Walt tests for EQS and EQSPC. Los Angeles, CA: BMDP Statistical Software.

Bentler, P. M. (1990). Comparative fit indexes in structural models. Psychol. Bull. 107, 238-246. doi: 10.1037/0033-2909.107.2.238

Briggs, S. R., and Cheek, S. M. (1986). The role of factor analysis in the development and evaluation of personality scales. J. Pers. 54, 106-148. doi: 10.1111/j.1467-6494.1986.tb00391.x

Browne, M. W., and Cudeck, R. (1993). “Alternative ways of assessing model fit," in Testing Structural Equation Models, eds K. A. Bollen and J. S. Long (Thousand Oaks, CA: Sage Publications), 136-162.

Carretero-Dios, H., and Pérez, C. (2007). Standards for the development and review of instrumental studies: considerations about test selection in psychological research. Int. J. Clin. Health Psychol. 7, 863-882. Available online at: http://www.aepc.es/ijchp/carretero_es.pdf

Ceschi, A., Sartori, R., Dickert, S., and Costantini, A. (2016). Grit or honestyhumility? new insights into the moderating role of personality between the health impairment process and counterproductive work behavior. Front. Psychol. 7:1799. doi: 10.3389/fpsyg.2016.01799 psychological and educational variables, as has been done in English-speaking populations with the original version of the scale.

\section{ETHICS STATEMENT}

This study was carried out in accordance with the recommendations of the ethics committees of NetQuest and UPF with written informed consent from all subjects. All subjects gave written informed consent in accordance with the Declaration of Helsinki. The protocol was approved by the ethics committees of NetQuest and UPF.

\section{AUTHOR CONTRIBUTIONS}

JA-T and FF-M were responsible for adapting and validating the scale that was used later in a larger research project; both authors participated actively in the process of translating the original English scale into Spanish as well as supervised the implementation process of the survey; both authors clean the resulting database and did the statistical analysis necessary to validate the English version with Spanish population, including the discussion section and the references part. $\mathrm{RH}$ supervised and replicated the data analysis process as well as the reporting process of the results particularly the proofreading of the paper in English.

\section{FUNDING}

This work is an outcome of the EU-funded collaborative research project "Cultural Pathways to Economic Self-Sufficiency and Entrepreneurship" (CUPESSE; Grant Agreement No. 613257; www.cupesse.eu). RH was funded by grant P30DA023026 from the National Institute on Drug Abuse during the writing of this manuscript.
Chou, C. P., and Bentler, P. M. (1990). Model modification in covariance structure modeling: a comparison among likelihood ratio, lagrange multiplier, and wald tests. Multivariate Behav. Res. 25, 115-136. doi: 10.1207/s15327906mbr2501_13

Couper, M. P., and Bosnjak, M. (2010). "Internet surveys," in Handbook of Survey Research, eds P. V. Mardsen and J. D. Wright (Bingley: Emerald Group), 527-550.

Credé, M., Tynan, M. C., and Harms, P. D. (2017). Much ado about grit: a metaanalytic synthesis of the grit literature. J. Pers. Soc. Psychol. 113, 492-511. doi: $10.1037 /$ pspp0000102

Duckworth, A. L., and Eskreis-Winkler, L. (2015). “Grit," in International Encyclopedia of the Social \& Behavioral Sciences, 2nd Edn., eds D. W. James (Oxford: Elsevier), 397-401.

Duckworth, A. L., and Quinn, P. D. (2009). Development and validation of the short grit scale (GRIT-S). J. Pers. Assess. 91, 166-174. doi: 10.1080/00223890802634290

Duckworth, A. L., Peterson, C., Matthews, M. D., and Kelly, D. R. (2007). Grit: perseverance and passion for long-term goals. J. Pers. Soc. Psychol. 92, 1087-1101. doi: 10.1037/0022-3514.92.6.1087

Duckworth, A. L., Quinn, P. D., and Seligman, M. E. P. (2009). Positive predictors of teacher effectiveness. J. Posit. Psychol. 4, 540-547. doi: 10.1080/17439760903157232

Eskreis-Winkler, L., Shulman, E. P., Beal, S. A., and Duckworth, A. L. (2014a). The grit effect: predicting retention in the military, the workplace, 
school and marriage. Front. Psychol. 5:36. doi: 10.3389/fpsyg.2014. 00036

Eskreis-Winkler, L., Shulman, E. P., and Duckworth, A. L. (2014b). Survivor mission: do those who survive have a drive to thrive at work? J. Posit. Psychol. 9, 209-218. doi: 10.1080/17439760.2014.888579

Fernández-Martín, F. D., Arco-Tirado, J. L., and Soriano, M. (2017). Perseverancia y Passion por la Consecución de Objetivos a Largo Plazo: Adaptación Transcultural y Validación de la Escala Grit-S. [Perseverance and Passion for Long-Term Objectives: Transcultural Adaptation and Validation of the Grit-S scale].

Fleckenstein, J., Schmidt, F. T. C., and Möller, J. (2014). Wer hat Biss? Beharrlichkeit und beständigesInteresse von lehramt studierenden: eine deutsche adaptation der 12-Item grit scale [Who's got grit? perseverance and consistency of interest in pre-service teachers: a german adaptation of the 12-Item grit scale]. Psychol. Erziehung Unterricht 61, 281-286. doi: 10.2378/peu2014.art22d

Haer, R., and Meidert, N. (2013). Does the first impression count? Examining the effect of the welcome screen design on the response rate. Surv. Methodol. 39, 419-434. Available online at: http://www.statcan.gc.ca/pub/12-001-x/2013002/ article/11885-eng.htm

Hu, L., and Bentler, P. M. (1999). Cutoff criteria for fit indexes in covariance structure analysis: conventional criteria versus new alternatives. Struct. Equat. Model. A Multidiscipl. J. 6, 1-55. doi: 10.1080/10705519909540118

Jachimowicz, J. M., Wihler, A., and Galinsky, A. D. (2017). The dual pillars of grit: the synergistic benefits of combining perseverance and passion alignment for job performance. PsyArXiv. doi: 10.17605/OSF.IO/H9473. [Epub ahead of print].

Kim, Y. J., and Lee, C. S. (2015). Effects of grit on the successful aging of the elderly in Korea. Indian J. Sci. Technol. 8, 373-378. doi: 10.17485/ijst/2015/v8iS7/70421

López-Walle, J., Balaguer, I., Mei,á, J. L., Castillo, I., and Tristán, J. (2011). Adaptación a la población mexicana del Cuestionario de Orientación al Ego ya la Tarea en el Deporte (TEOSQ) [Adaptation to mexican population of the orientation to ego and to the task in sport questionnaire]. Rev. Psicol. Dep. 20, 523-536. Available online at: http://www.redalyc.org/articulo.oa?id= 235122167019

Muenks, K., Wigfield, A., Yang, J. S., and O'Neal, C. R. (2017). How true is Grit?: assessing its relations to high school and college students' personality characteristics, self-regulation, engagement, and achievement. J. Educ. Psychol. 109, 599-620. doi: 10.1037/edu0000153

Muñiz, J., Elosua, P., and Hambleton, R. K. (2013). Directrices para la traducción y adaptación de los tests: Segunda edición [Guidelines for the translation and adaptation of tests: Second edition]. Psicothema 25, 151-157. doi: 10.7334/psicothema2013.24

Nishikawa, K., Okugami, S., and Amemiya, T. (2015). Development of the Japanese grit scale (Grit-S). Jpn. J. Pers. 24, 167-169. doi: 10.2132/personality.24.167

Nunnally, J. C., and Bernstein, I. J. (1994). Psychometric Theory, 3rd Edn. New York, NY: MacGraw Hill.

Rimfeld, K., Kovas, Y., Dale, P. S., and Plomin, R. (2016). True grit and genetics: predicting academic achievement from personality. J. Pers. Soc. Psychol. 111, 780-789. doi: $10.1037 /$ pspp0000089

Roberts, B. W., Lejuez, C., Krueger, R. F., Richards, J. M., and Hill, P. I. (2014). What is conscientiousness and how can it be assessed. Dev. Psychol. 50, 1315-1330. doi: 10.1037/a0031109
Sartori, R., and Pasini, M. (2007). Quality and quantity in test validity: how can we be sure that psychological tests measure what they have to? Quality Quantity 41, 359-374. doi: 10.1007/s11135-006-9006-x

Sartori, R., Costantini, A., Ceschi, A., and Scalco, A. (2017). Not only correlations: a different approach for investigating the relationship between the big five personality traits and job performance based on workers and employees' perception. Quality Quantity 51, 2507-2519. doi: 10.1007/s11135-0160406-2

Satorra, A., and Bentler, E. M. (1988). "Scaling corrections for chi-square statistics in covariance structure analysis. ASA 1988," in Proceedings of the Business and Economic Statistics Section (Alexandria, VA: American Statistical Association), 308-313.

Satorra, A., and Bentler, P. M. (2001). A scaled difference chi-square test statistic for moment structure analysis. Psychometrika 66, 507-514. doi: $10.1007 / \mathrm{BF} 02296192$

Steiger, J. H., and Lind, J. C. (1980). "Statistically based tests for the number of factors," Paper Presented at the Annual Meeting of the Psychometric Society (Iowa City).

Steiger, J. H., Shapiro, A., and Browne, M. W. (1985). On the multivariate asymptotic distribution of sequential chi-square statistics. Psychometrika 50, 253-264. doi: 10.1007/BF02294104

Survey Research Center (2016). "Translation: Overview," in Guidelines for Best Practice in Cross-Cultural Surveys, 4th Edn., ed Survey Research Center (Ann Arbor, MI: Survey Research Center, Institute for Social Research, University of Michigan), 233-285.

Tedesqui, R. A. B., and Young, B. W. (2018). Comparing the contribution of conscientiousness, self-control, and grit to key criteria of sport expertise development. J. Sport Exerc. 34, 110-118. doi: 10.1016/j.psychsport.2017. 10.002

Tyumeneva, Y., Kuzmina, J., and Kardanova, E. (2014). IRT analysis and validation of the Grit Scale: A Russian investigation (Working Paper BRP 24/PSY/2014). Higher School of Economics, National Research University. Available online at: http://www.hse.ru/data/2014/11/19/1101023281/24PSY2014.pdf

Von Culin, K. R., Tsukayama, E., and Duckworth, A. L. (2014). Unpacking grit: motivational correlates of perseverance and passion for longterm goals. J. Positive Psychol. 9, 306-312. doi: 10.1080/17439760.2014. 898320

Yeager, D. S., Henderson, M. D., Paunesku, D., Walton, G. M., D’Mello, S., Spitzer, B. J., et al. (2014). Boring but important: a self-transcendent purpose for learning fosters academic self-regulation. J. Pers. Soc. Psychol. 107, 559-580. doi: $10.1037 / \mathrm{a} 0037637$

Conflict of Interest Statement: The authors declare that the research was conducted in the absence of any commercial or financial relationships that could be construed as a potential conflict of interest.

Copyright $(2018$ Arco-Tirado, Fernández-Martín and Hoyle. This is an open-access article distributed under the terms of the Creative Commons Attribution License (CC $B Y)$. The use, distribution or reproduction in other forums is permitted, provided the original author(s) and the copyright owner are credited and that the original publication in this journal is cited, in accordance with accepted academic practice. No use, distribution or reproduction is permitted which does not comply with these terms. 